\title{
Intensive follow-up for women with breast cancer: review of clinical, economic and patient's preference domains through evidence to decision framework
}

\author{
Alessandra Lafranconi ${ }^{1,2,4+}$, Liisa Pylkkänen ${ }^{3,4 \dagger}$, Silvia Deandrea ${ }^{4 *}$ (D, Anke Bramesfeld ${ }^{4}$, Donata Lerda ${ }^{4}$, \\ Luciana Neamțiu ${ }^{4}$, Zuleika Saz-Parkinson ${ }^{4}$, Margarita Posso ${ }^{5}$, David Rigau ${ }^{5}$, Ivan Sola, Pablo Alonso-Coello ${ }^{5}$ \\ and Maria José Martinez-Zapata ${ }^{5}$
}

\begin{abstract}
Background: Women treated for breast cancer are followed-up for monitoring of treatment effectiveness and for detecting recurrences at an early stage. The type of follow-up received may affect women's reassurance and impact on their quality of life. Anxiety and depression among women with breast cancer has been described, but little is known about how the intensity of the follow-up can affect women's psychological status. This study was undertaken to evaluate the effects of intensive vs. less-intensive follow-up on different health outcomes, to determine what are women's preferences and values regarding the follow-up received, and also assess the costs of these different types of follow-up.

Methods: A systematic review following standard Cochrane Collaboration methods was carried out to assess the efficacy of intensive follow-up versus non-intensive follow-up in breast cancer patients. Two additional reviews on women's preferences and economic evidence were also carried out. The search was performed up to January 2016 in: MEDLINE, EMBASE, PDQ, McMaster Health Systems Evidence, CENTRAL, and NHS EED (through The Cochrane Library). The quality of evidence was assessed by GRADE (for quantitative studies) and CerQUAL (for qualitative studies). Several outcomes including mortality, breast cancer recurrences, quality of life, and patient satisfaction were evaluated.

Results: Six randomised trials (corresponding to 3534 women) were included for the evaluation of health outcomes; three studies were included for women's values and preferences and four for an economic assessment. There is moderate certainty of evidence showing that intensive follow-up, including more frequent diagnostic tests or visits, does not have effects on 5- or 10-year overall mortality and recurrences in women with breast cancer, compared with less intensive follow-up. Regarding women's preferences and values, there was important variability among studies and within studies (low confidence due to risk of bias and inconsistency). Furthermore, intensive follow-up, as opposed to less intensive follow-up, is not likely to be cost-effective.
\end{abstract}

Conclusions: Less intensive follow-up appears to be justified and can be recommended over intensive follow-up. Resources could thus be mobilised to other aspects of breast cancer care, or other areas of healthcare.

Keywords: Breast cancer, Follow-up, Recommendation, EtD framework

\footnotetext{
* Correspondence: Silvia.DEANDREA@ec.europa.eu; jrc-cancer-policysupport@ec.europa.eu

${ }^{\dagger}$ Equal contributors

${ }^{4}$ European Commission, Directorate General Joint Research Centre (JRC), Directorate F - Health, Consumers and Reference Materials, Ispra, VA, Italy Full list of author information is available at the end of the article
} 


\section{Background}

Breast cancer is the most frequently diagnosed cancer and among the leading causes of cancer death among females [1-3]. Due to significant improvements in screening, early diagnosis, and treatment in the recent decades, breast cancer mortality has decreased worldwide [4-6]. This leads to a situation where the total number of prevalent breast cancer cases is increasing, and therefore a growing number of women needing follow-up care. Worldwide and European estimates of women with a diagnosis of breast cancer occurring in the last 5 years correspond to 6.2 and 1.8 million, respectively [7].

Women treated for breast cancer are followed-up for monitoring treatment effectiveness and complications, and for detecting recurrences at an early stage or new primary contralateral breast cancer. Follow-up includes clinical and test examinations such as routine haematological and liver function tests, tumour markers, chest $\mathrm{X}$-ray, mammography and bone and liver scans [8]. The diversity in frequency and in the type of examination results in many different follow-up practices, the intensity of which can be defined by the frequency of clinical visits and/or physical examinations (e.g. intensive, standard, patient-initiated or low intensity). There is also evidence of variability [9] in the way follow-up is implemented in clinical practice.

Despite doubts that intensive follow-up care can improve survival in these patients, intensive follow-up is quite common in clinical practice and represents a significant workload for radiotherapy, surgical and oncologic departments [10].

For a long time, the scientific community has focused on the relationship between the type of follow-up (i.e. intensity) and health outcomes, such as long-term mortality and morbidity, but also quality of life. A recent Cochrane review that analysed randomised control trials with almost 20 years of follow-up gave the following suggestion: "follow-up programs based on regular physical examinations and yearly mammography alone are as effective as more intensive approaches based on regular performance of laboratory and instrumental tests in terms of timeliness of recurrence detection, overall survival and quality of life" [11].

Despite the importance of health outcomes in terms of mortality and morbidity, it is also important to take into account the women's perspective, including psychosomatic symptoms and diseases, which could be manifested as preference towards one or another type of follow-up scheme [12]. Similarly, economic evidence in healthcare is becoming increasingly important, not only in the form of cost-effectiveness or cost-utility analyses, which are the most common mechanism for generating economic evidence in decision making, but also in the form of cost-minimisation, cost-consequences or cost- benefit analyses or total budget impact estimates [13]. This is another key point to be considered in recommending a certain type of follow-up protocol.

Given that all these aspects should be considered together to make decisions in healthcare, there is an urgent need to use up-to-date and user-friendly evidencepresentation formats, in order to improve the communication of evidence-based healthcare recommendations, addressing communication needs of guideline users and decision-makers [14]. The Grading of Recommendations Assessment, Development, and Evaluation (GRADE) methodology [15-17] in combination with Evidence to Decision (EtD) Frameworks provides an assessment and a summary of alternative strategies on three key elements: patient-important outcomes, patients' values and preferences, and economic evidence. Information regarding acceptability and feasibility of the analysed strategies, and their impact on health equity is also included $[15,18]$.

The aim of the present paper is to evaluate the available research evidence on the clinical question about whether intensive follow-up should be provided for breast cancer patients treated with curative intent. The evidence is assessed and summarised according to GRADE and the EtD framework; the recommendations made in this manuscript are based on the authors judgements and should only be considered as the authors' recommendations and not as recommendations made by a guideline panel. Nevertheless, they are useful to facilitate the further decision-making process carried out by guideline panels in charge of issuing clinical recommendations.

\section{Methods}

Systematic review on the evidence of effects of intensive follow-up on breast cancer outcomes

The research question was addressed by means of a systematic review of the literature on the evidence of health outcomes related to the alternative strategies - intensive and less intensive follow-up. An operational definition was used for intensive follow-up, where intensive was defined in comparison with a less intensive follow-up schedule or a patient-initiated approach. The review protocol is available upon request. Standard Cochrane Collaboration methods were followed [19]. For the evaluation of the importance of the outcomes and for the assessment of the quality of evidence, the GRADE system was used.

Research question: the clinical question was structured following the PICO (Patient, Intervention, Comparison, Outcomes) format:

- Population: breast cancer patients, treated with curative intent;

- Intervention: intensive follow-up schedule;

- Comparison: non-intensive follow-up; 
- Outcomes: 5- and 10-year mortality due to breast cancer; 5 and 10-year breast cancer recurrences (loco-regional and distant separately); 5- and 10-year breast cancer specific survival; quality of life at 2 and 5 years after diagnosis; women's satisfaction with follow-up (measured by reassurance of women with the intensive follow-up and convenience by the women of intensive follow-up).

Critical outcomes included mortality due to breast cancer, breast cancer recurrences and breast cancer specific survival. Quality of life and satisfaction were considered important outcomes.

\section{Inclusion and exclusion criteria}

Following the WHO Handbook for Guidelines Development [20] as guidance, existing relevant systematic reviews of observational and experimental evidence were included as a source of individual studies; additional individual studies were searched, to update the body of evidence. Temporal or language restrictions were not applied. Studies in which the effects of follow-up intensity were not assessed, or when the outcomes were out of the scope of the clinical question, were excluded.

\section{Search strategy}

Systematic reviews were identified by introducing a combination of controlled vocabulary and search terms (e.g., follow-up, breast neoplasms, mortality, recurrences, quality of life, satisfaction, cost, healthcare resources, survival) in The Cochrane Database of Systematic Reviews (2015, issue 11), The Database of Abstracts of Reviews of Effects (DARE), and PubMed limiting the search to the subset "systematic $[\mathrm{sb}]$ ".

Original studies were searched in MEDLINE (through PubMed; from 1946 to January 2016), EMBASE (through Ovid; from 1980 to November 2015), PDQ, McMaster Health Systems Evidence, CENTRAL, and NHS EED (through The Cochrane Library; January 2016).

The complete search algorithms designed for each database, the hits retrieved, and the reasons for exclusion are presented in Additional file 1 and Fig. 1a.

One reviewer screened the search results based on title and abstract. This process was subjected to a quality process, by reviewing $20 \%$ of the references by a second reviewer. Two reviewers independently confirmed eligibility, based on the full text of the relevant articles. In case of disagreement between reviewers the inclusion of studies was determined by consensus.

\section{Data extraction}

Data extraction was conducted by one reviewer. As quality control, another reviewer went through $20 \%$ of the data for accuracy.

\section{Risk of bias}

The assessment was carried out by one reviewer. As quality control, another reviewer went through $20 \%$ of the data for accuracy. For each study, the risk of bias was rated for each domain as low, high or unclear risk of bias.

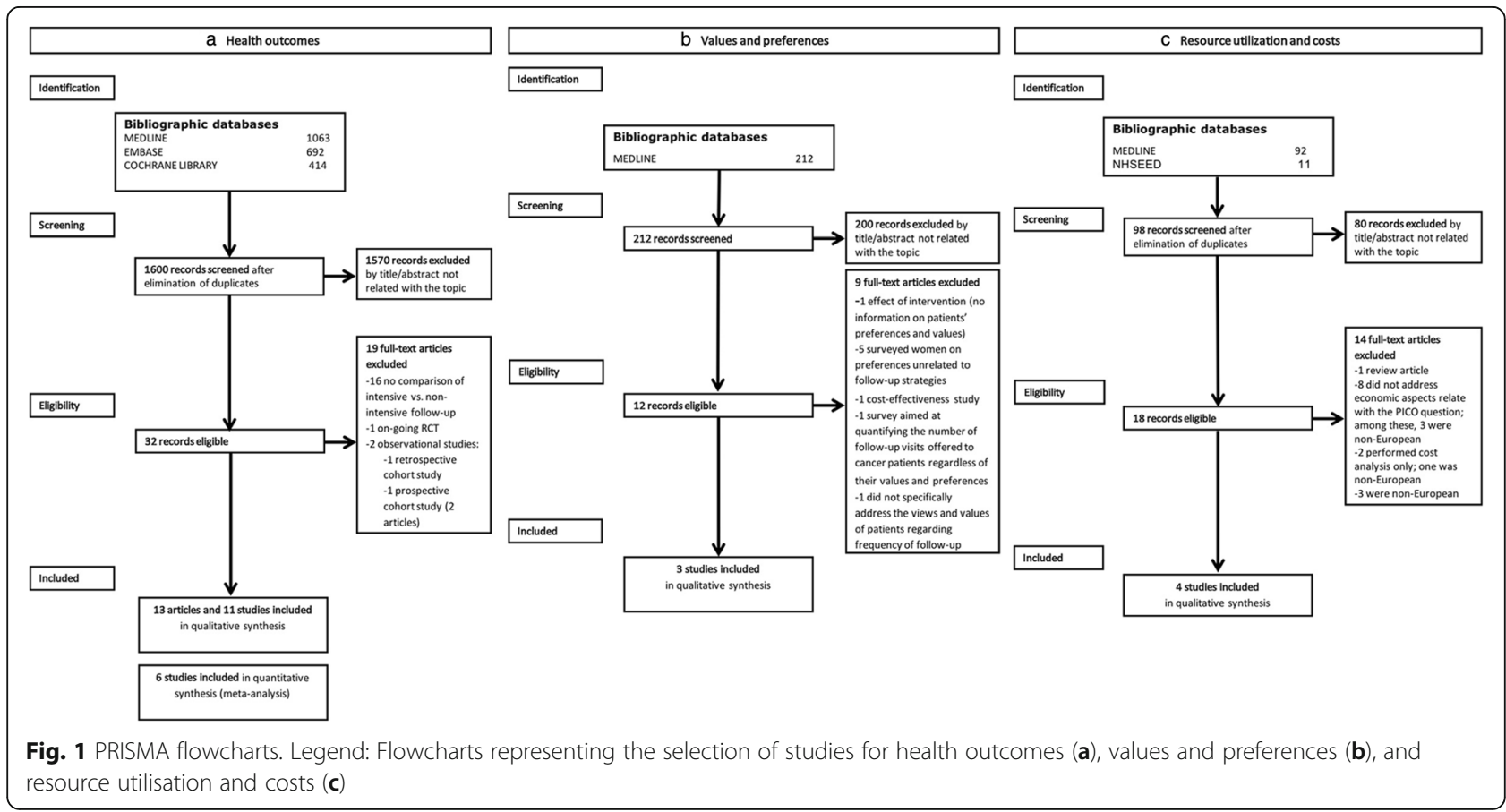




\section{Effect measures}

Odds ratios (OR), risk ratios (RR) and hazard ratios (HR) were extracted, with their 95\% confidence intervals (CI). If available, only adjusted effect measures were collected. Data from any estimation of effect provided (percentages, means, medians) were also collected.

\section{Quality of the evidence evaluation}

The quality of evidence per outcome was rated from high to very low considering the standard GRADE domains: risk of bias, imprecision, inconsistency, indirectness and publication bias $[21,22]$.

\section{Data analysis}

A pooled analysis was conducted applying the inversevariance method under the random-effects model [23]; the analysis was performed through the Software Review Manager v. 5.3. Heterogeneity was assessed using the $\mathrm{I}^{2}$ statistic.

The report of results of the meta-analysis adhered to the guidelines articulated in the Preferred Reporting Items for Systematic Reviews and Meta-Analyses (PRISMA) statement [24].

\section{Review on women's values and preferences}

A review about women's values and preferences for intensive follow-up versus non-intensive follow-up after breast cancer treatment was undertaken.

\section{Inclusion and exclusion criteria}

In a first stage, after conducting the systematic search of the literature, the screening of references was carried out, initially prioritising the identification of systematic reviews. In a second stage, individual studies were retrieved (e.g., qualitative studies, surveys, utility elicitation studies). Studies in English, French, German, Greek, and Spanish, carried out in the Organisation for Economic Co-operation and Development (OECD) Region, were included. Included studies were:

- examining women's preferences for follow-up strategies after breast cancer treatment;

- evaluating how women value the main outcomes associated with follow-up strategies after breast cancer treatment;

- examining the choices women make when informed about the desirable and undesirable effects associated with follow-up strategies after breast cancer treatment.

Studies assessing only women's knowledge, views, perceptions, attitudes and expectations regarding follow-up strategies after breast cancer treatment were excluded; similarly, studies assessing barriers to follow-up strategies after breast cancer treatment were not included.

\section{Search strategy}

A search strategy was designed to identify relevant studies in MEDLINE (accessed through Ovid). For systematic reviews, there were no time restrictions. For primary studies, only studies published after 2006 were included. The complete search strategy can be found in Additional file 2.

One reviewer screened the search results based on the title and abstract. Two reviewers independently confirmed eligibility based on the full text of the relevant articles. In case of disagreement between researchers, the inclusion of studies was decided by consensus (Fig. 1b).

\section{Data extraction}

One reviewer extracted the main characteristics of the included studies and their findings in a tabulated format. A second reviewer checked the extracted data for accuracy.

\section{Quality of the evidence evaluation}

The quality of evidence was rated with GRADE. In the case of qualitative research, the Confidence in the Evidence from Reviews of Qualitative research (CERQual) approach was used [25].

\section{Review on economic evidence}

A review about the economic evidence for intensive follow-up versus non-intensive follow-up after breast cancer treatment was carried out.

\section{Inclusion and exclusion criteria}

Screening of literature and study selection was done in a step-by- step approach. Firstly, the search focused on studies that addressed economic aspects directly related to the PICO question. Then, recent European costeffectiveness or cost-utility analyses related to the PICO question were looked for. Only studies in English were included.

\section{Search strategy}

Search strategies were designed to identify relevant studies in MEDLINE (through Ovid, January 2016) and in the NHS Economic Evaluation Database (through The Cochrane Library, January 2016). The complete search strategies are included in Additional file 3. Study design filters were applied to retrieve relevant studies. The selection process is presented in Fig. 1c.

\section{Data extraction}

Main characteristics of included studies were described in a tabulated format, including the following data: author and publication year, country, type of economic analysis, perspective of the analysis, time horizon and discounting, relevant outcomes and costs included, 
sources of information (baseline outcomes, relative intervention effects, resource use and costs), Quality Adjusted Life Years (QALY), Incremental Cost Effectiveness Ratio (ICER), sensitivity analysis and conflict of interest.

\section{Quality of evidence}

The quality of evidence for the resource requirements was rated according to GRADE [26]. The NICE methodology checklist for economic evaluations [27] was used to assess the risk of bias and decide whether to include the studies. Included studies were of low risk of bias and were considered applicable to the European context.

\section{Evidence to decision framework}

To summarise the evidence, and in accordance to the GRADE methodology [28] and the interactive Evidence to Decision framework guidance [29], an EtD Framework was developed. The authors covered the role of the panel with respect to the EtD framework.

\section{Results}

Evidence of effects of intensive follow-up on breast cancer outcomes

Five systematic reviews were included for the evaluation of health outcomes [30-34]. These systematic reviews were used as a source to identify primary studies. Eight papers, referring to six randomised clinical trials for a total of 3534 randomised women [35-42], were retrieved and included. These studies are summarised in Table 1.

The included studies had different definitions for intensive follow-up. In four studies, intensive follow-up referred to a greater number of diagnostic tests compared to regular follow-up [35, 36, 40, 42], while in two studies it referred to more frequent visits without modification in the number of diagnostic tests [37, 39]. Three studies compared an intensive versus a standard follow-up [35, $36,42]$, while the other three compared a low-intensity patient-initiated versus a standard follow-up [37, 39, 40]. Five studies specified that patients (including the nonintensive follow-up group) underwent an annual mammography [35-38, 42]. No studies provided information about specific breast cancer mortality or survival. Among all studies, only the one carried out by the GIVIO group [35] reported the expected 5-year relative mortality reduction used for the calculation of sample size, i.e. $20 \%$ reduction; this threshold may be considered as the clinically significant mortality reduction expected.

Results and pooled analysis are provided when possible. Quantitative estimates are available only for the following outcomes, presented in Fig. 2:

10-year overall mortality: one trial [38], that compared intensive vs. standard follow-up in 1243 women, found a $\mathrm{RR}=1.05$ (95\%CI: 0.90 to 1.22 ). The quality of evidence was high because non-blinding was not considered a cause of risk of bias for this outcome.

5 -year overall mortality: three trials [35, 36, 40], on 3035 patients, that compared intensive vs. standard follow-up found a RR 1.00 (95\%CI: 0.86 to 1.16; $\mathrm{I}^{2}=0 \%$ ). The 5-year mortality RR lower $95 \% \mathrm{CI}$ did not reach the expected value for clinical significance either (vs. an expected $20 \%$ mortality reduction, as per GIVIO group outcome). The quality of evidence was high because non-blinding was not considered a cause of risk of bias for this outcome.

5-year breast cancer recurrences (any loco-regional and distant): three trials [35, 36, 40], on 3035 patients, that compared intensive and standard follow-up, resulted in a $\mathrm{RR}=1.08\left(95 \% \mathrm{CI}: 0.89\right.$ to $\left.1.30 ; \mathrm{I}^{2}=60 \%\right)$. The quality of evidence was moderate because it was downgraded for risk of bias (the outcome assessment was not blinded). From the clinical point of view, when the patient is diagnosed with recurrence, there will be an initiation of new treatments or change in the treatment, so we considered that non-blinding is not an issue in this case.

Breast cancer recurrences at any time: five trials [35, $36,39,40,42]$, on 3217 women, found a $R R=1.10$ (95\%CI: 0.95 to $1.27 ; \mathrm{I}^{2}=23 \%$, when comparing intensive vs. standard follow-up. The quality of evidence was moderate because it was downgraded for risk of bias (the outcome assessment was not blinded). As discussed above, non-blinding was not considered as an issue.

Satisfaction of women with the type of follow-up: satisfaction was measured as reassurance (capacity of the type of follow-up to clear patients' doubts or fears) in two studies [37, 39] on 245 patients, and as convenience (suitability of the follow-up to the woman's life circumstances) in one study [39] on 61 women. The results on reassurance were in favour of intensive follow-up (RR 1.28, $95 \%$ CI: 1.07 to $1.54 ; \mathrm{I}^{2}=90 \%$ ). The overall quality of evidence was very low due to risk of bias (the studies were not blinded) and imprecision (the number of events is small). The results on convenience favoured non-intensive follow-up (RR 0.04, 95\%CI: 0.01 to 0.31). The overall quality of evidence was low because evidence needed to be downgraded for risk of bias (the outcome assessment was not blinded) and imprecision (the number of events is very small).

For each studied outcome, the evidence profile is reported in Table 2 .

\section{Women's values and preferences}

For women's values and preferences, three European studies were included [37, 43, 44] (Table 3).

Gulliford et al. [37] compared experiences of 193 patients with breast cancer, randomised into a group with a conventional schedule of clinic visits, and a group of 


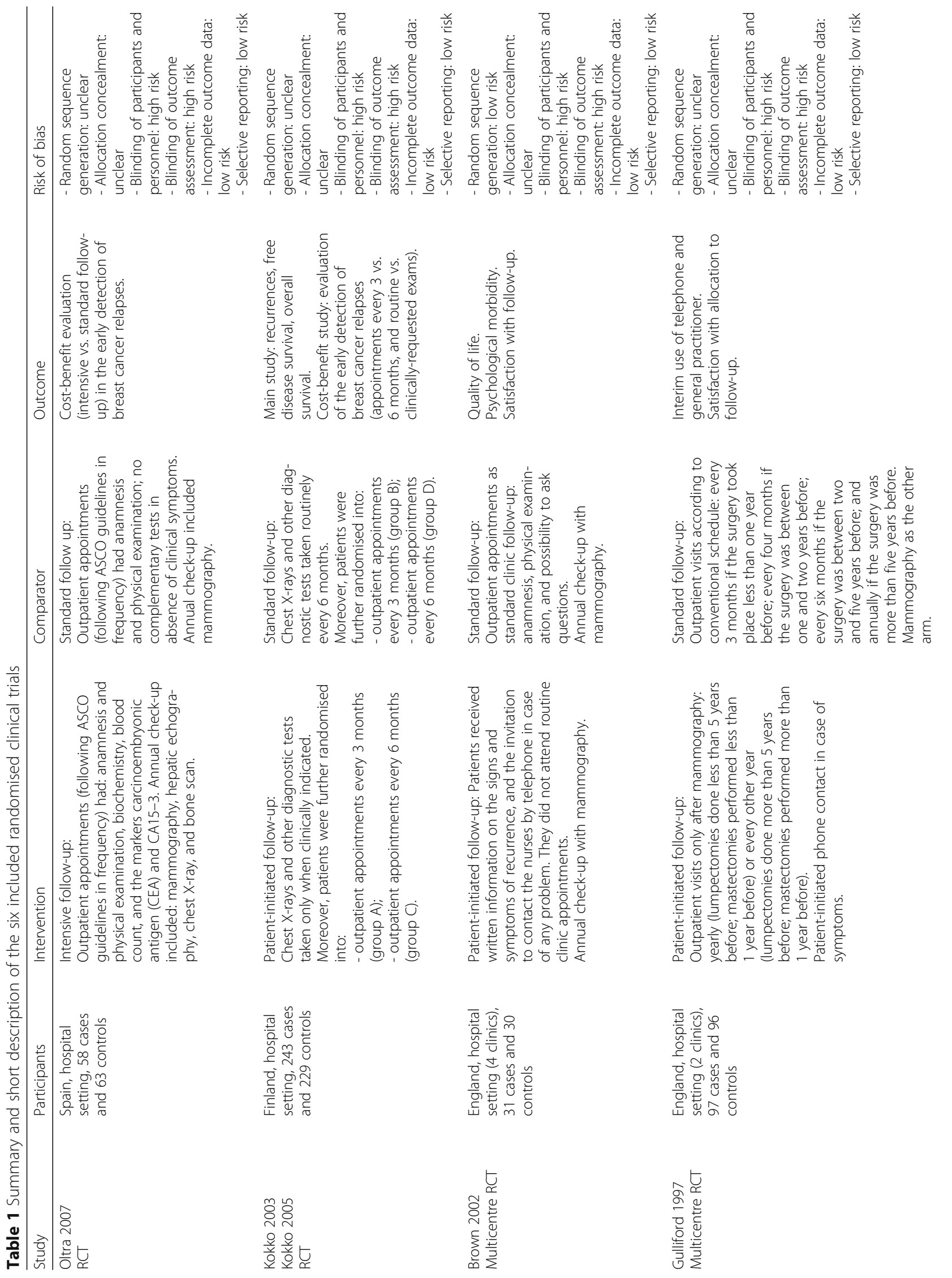




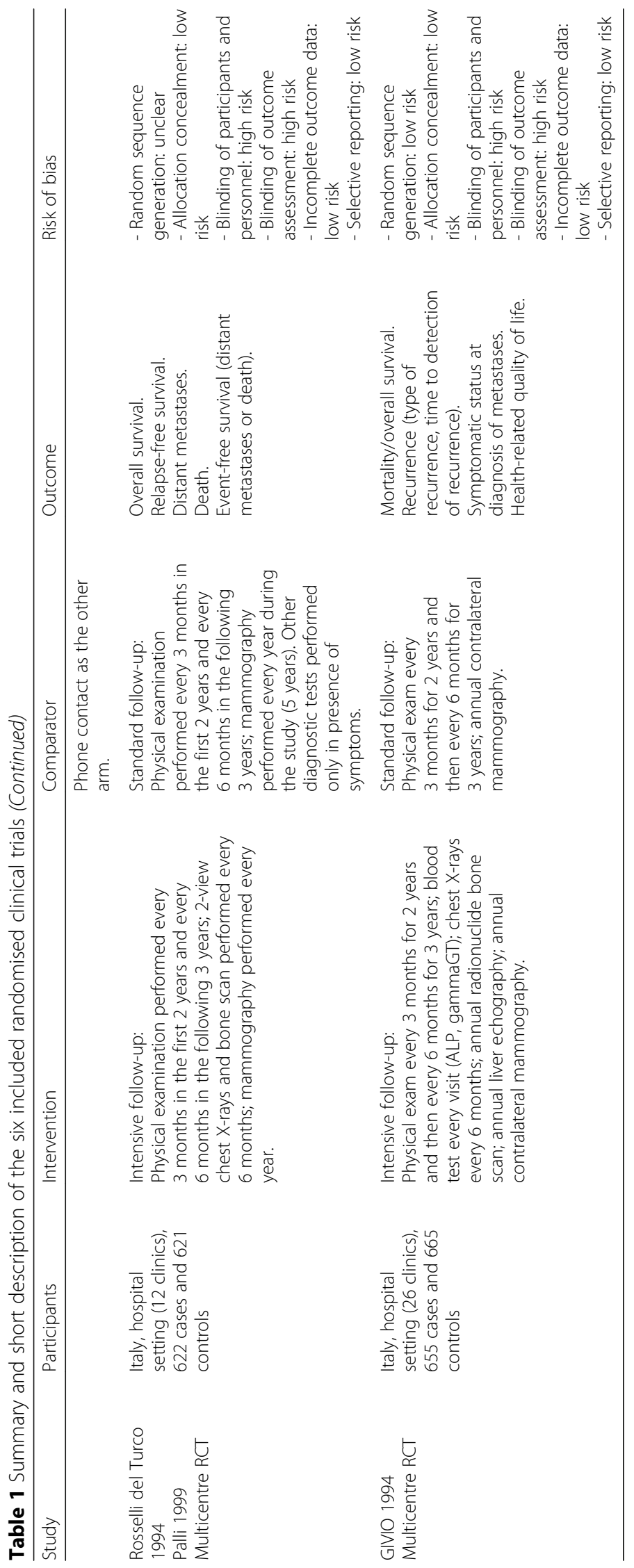




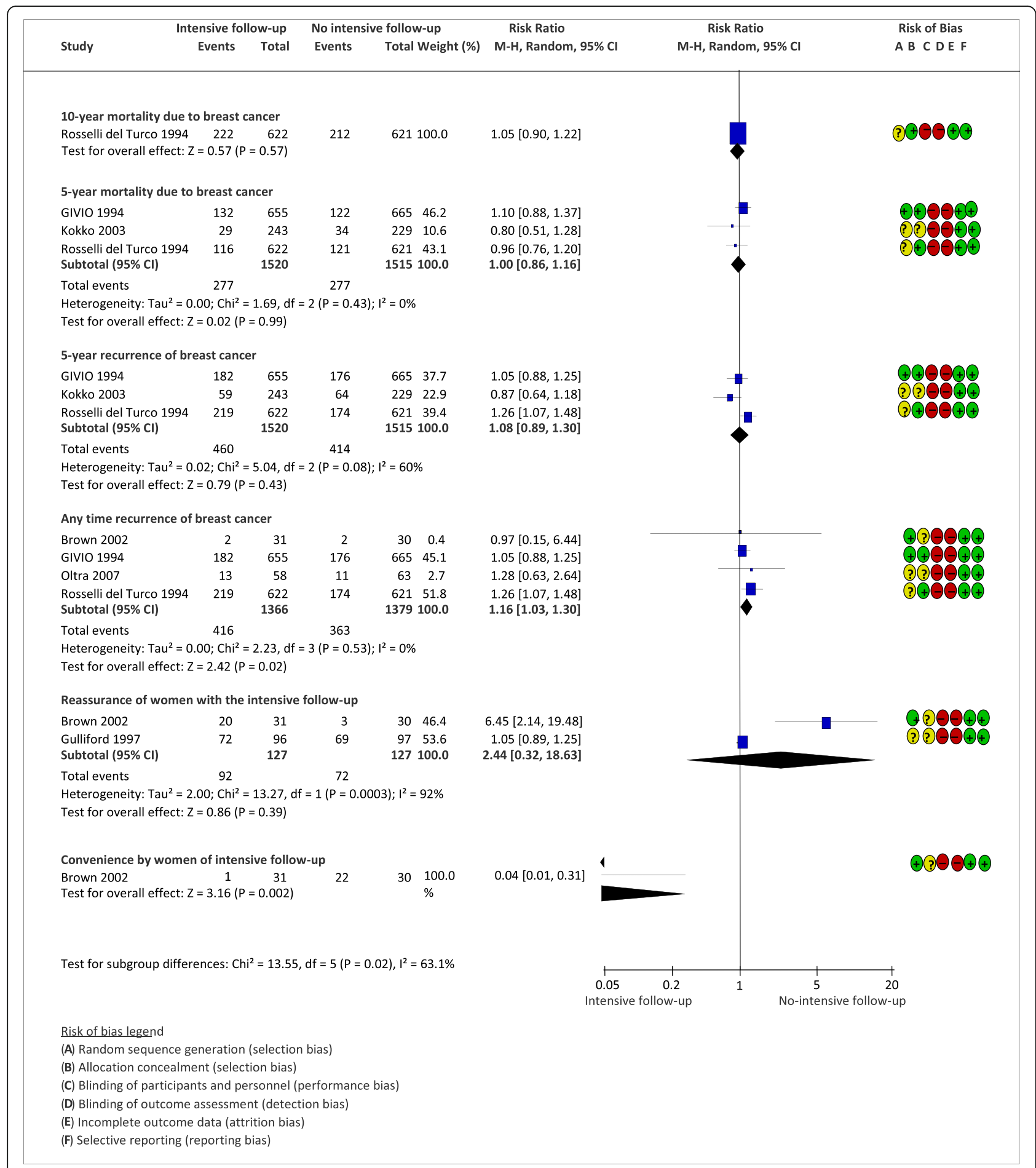

Fig. 2 Estimates of effect of intensive vs. standard follow-up on breast cancer outcomes

less intensive follow-up. Both cohorts received identical mammography and were invited to call for immediate appointments if they detected symptoms. Stemmler et al. [43] conducted a surveillance study in a population of women with breast cancer; among the respondents, most (59\%) belonged to an organised self-help group.
Kimman et al. [44] conducted a multicentre discretechoice experiment survey to measure the strength of preferences for several characteristics of breast cancer follow-up. The results of these three studies were inconsistent: in the first study, women appeared to prefer non-intensive follow-up schedules, while in the other 


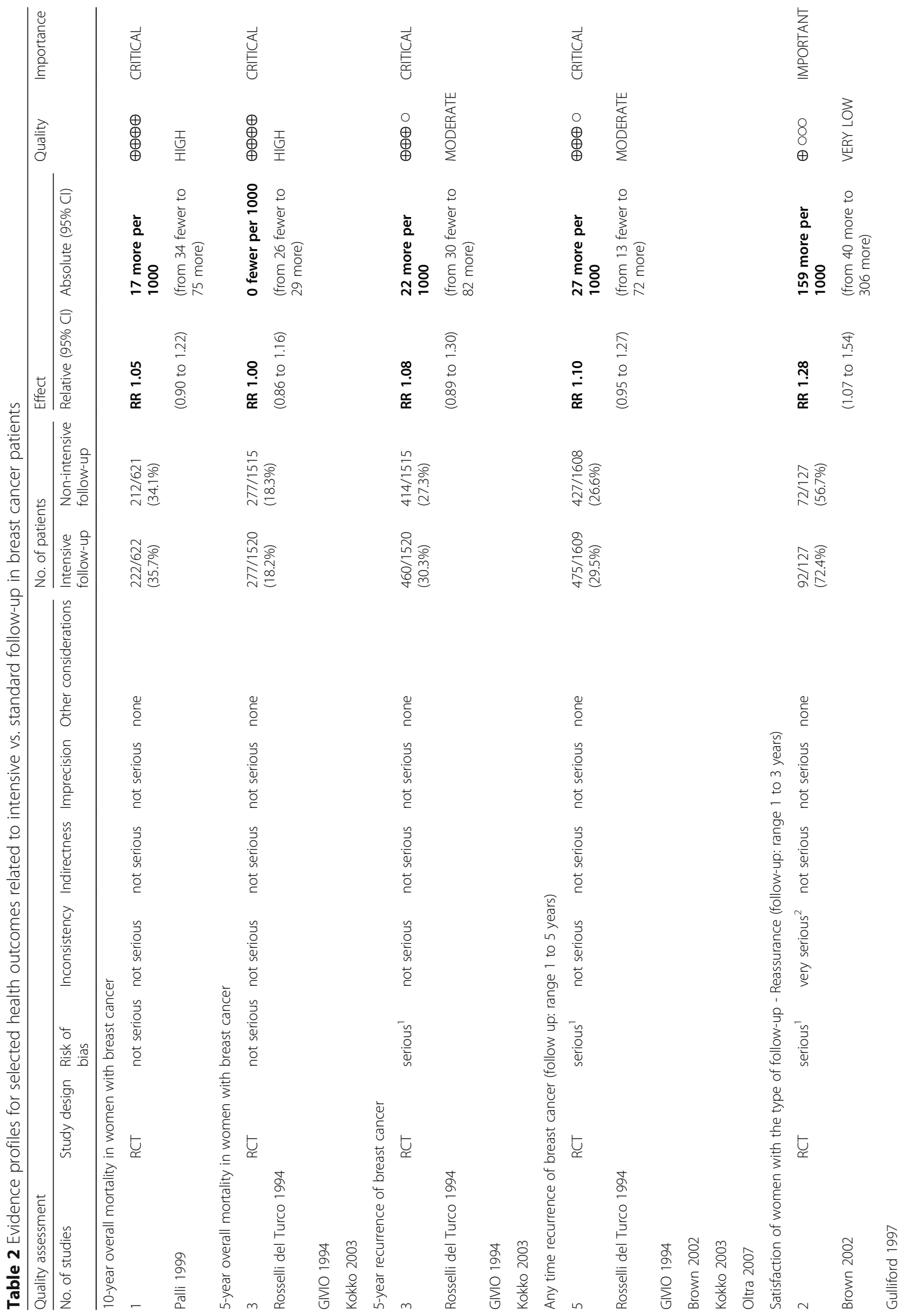




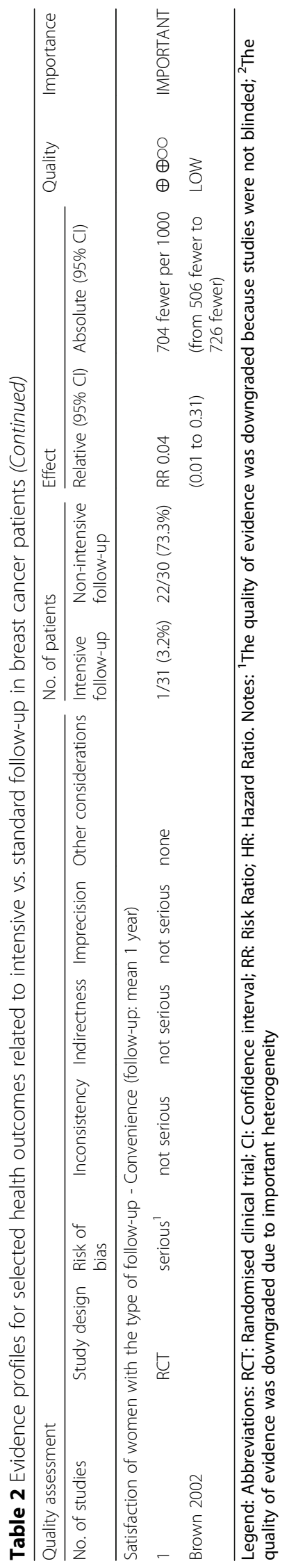


Table 3 Summary and short description of the three included studies on women's preferences and values

\begin{tabular}{llll}
\hline Study & Participants & Intervention & Results \\
\hline Gulliford 1997 & 96 patients in conventional & Comparison of conventional follow-up & Twice as many patients in both groups \\
RCT & follow-up and 95 patients in & (clinic visits, every three, four, six or & expressed a preference for reducing rather \\
& non-conventional follow-up & 12 months, based on the time distance & than increasing follow-up visits. \\
& from the surgery) with non- & No increased use of local practitioner \\
& $\begin{array}{ll}\text { conventional follow-up (clinical visits } \\
\text { every 12 or 24 months). Mammog- } \\
\text { raphy in both groups every 12 or }\end{array}$ & $\begin{array}{l}\text { services or telephone triage was recorded } \\
\text { in the group with less-intensive follow-up. }\end{array}$ &
\end{tabular}

$\begin{array}{lll}\begin{array}{l}\text { Stemmler } 2008 \\ \text { Questionnaire in } \\ \text { the context of a }\end{array} & \begin{array}{l}801(30.1 \%) \text { of } 2658 \text { eligible } \\ \text { patients }\end{array} & \begin{array}{l}\text { Survey aimed to evaluate patients' } \\ \text { views on surveillance after breast } \\ \text { cancer. }\end{array}\end{array}$

surveillance study
Kimman 2010

Multicentre

discrete-choice

experiment survey

$\begin{array}{ll}5 \text { hospitals, } 331 \text { (59\%) of } 557 & \text { Survey aimed to assess: } \\ \text { eligible patients } & \text { - preferred professional/s involved in } \\ & \text { follow-up; } \\ & \text { - preferred type of follow-up (in person } \\ & \text { vs telephone); } \\ & \text { - preferred follow-up schedule }\end{array}$

The majority of women confirmed the need for surveillance (95\%), and $47.8 \%$ of the patients in the self-help group answered that there was a need for more intensive diagnostic effort during follow-up. The main expectation from an intensified follow-up was the increased sense of security (80\%).

The most preferred person to perform follow-up was the medical specialist, but a combination of the medical specialist and breast care nurse was also acceptable to patients.

Face-to-face contact was strongly preferred over telephone contact.

Follow-up visits every three months were preferred over visits every four, six, or 12 months. two the preferences favoured intensive schedules. However, important variability was present among studies and within studies. There was low confidence in the evidence due to risk of bias and inconsistency.

The results of the review indicated that most of the regularly scheduled follow-up visits used further extensive laboratory and imaging procedures exceeding the quantity of examinations recommended in most of the current follow-up guidelines.

\section{Economic evidence}

Four studies [41, 42, 45, 46] assessed resources used, costs and cost-effectiveness of intensive follow-up strategies.

Robertson et al. [46] conducted a cost-utility analysis in the UK and provided estimated costs (in 2008 value) for different mammographic surveillance regimens in women after breast cancer surgery. By assuming the cost of a mammography and of a clinical follow-up visit to be 71 and $110 €$, respectively, in a cohort of $10,000 \mathrm{UK}$ women with a mean age of 57, total costs varied from 3.27 million $€$ (mammographic surveillance every 2 years) to 16.8 million $€$ (yearly mammographic and clinical follow-up) for a 10-year surveillance period. The study used a Markov model and found that the most costeffective strategy was surveillance with mammography alone, provided every 12 months since the incremental cost-effectiveness ratio (ICER) for this strategy compared to no surveillance was $€ 6051$ per QALY gained.

A cost-utility evaluation conducted in The Netherlands [45] analysed data (costs in 2008 value) on 299 patients randomised into four groups: (1) hospital follow-up; (2) nurse-led telephone follow-up; (3) hospital follow-up plus a short educational group programme (EGP); and (4) nurse-led telephone follow-up plus EGP. Hospital followup plus EGP had an ICER of $236 €$ per QALY compared to the next best alternative nurse-led telephone follow-up plus EGP. The other two strategies were dominated (higher costs and fewer QALYs). The authors concluded that nurse-led telephone follow-up combined with a short EGP could be a cost-effective option. However, they did not estimate the ICER of this strategy compared to standard follow-up. Furthermore, the time horizon of the study (one year) was clearly insufficient to evaluate the costeffectiveness of compared alternatives.

The study of Oltra et al. [42] found that an intensive follow-up characterised by multiple laboratory and imaging tests triples average costs of the standard clinical follow-up without differences in early detection of relapses during the three years of follow-up. The study of Kokko et al. [41] found that the most expensive strategy doubled the costs of the cheapest one without important differences in breast cancer recurrences among them.

The quality of the evidence on economic evidence was moderate due to indirectness. The study [56] considered in the evidence to decision framework was conducted in the UK, and the results may not be applicable to other European countries.

The EtD framework was applied to conclude the assessment. The research question is summarised in Table 4, while Table 5 represents the assessment, carried out in its 12 domains: among others, the certainty of evidence (e.g., no statistically significant differences in 
Table 4 Summary of the research question

\begin{tabular}{|c|c|c|c|}
\hline \multicolumn{4}{|c|}{ Should women be followed intensively after breast cancer treatment? } \\
\hline Problem: & $\begin{array}{l}\text { Women treated for breast cancer are followed-up for monitor- } \\
\text { ing treatment effectiveness and for detecting recurrences at an } \\
\text { early stage, but the frequency of follow-up is under discussion. }\end{array}$ & \multirow[t]{4}{*}{ Background: } & \multirow{4}{*}{$\begin{array}{l}\text { Women treated for breast cancer are followed up } \\
\text { for monitoring treatment effectiveness and for } \\
\text { detecting recurrences at an early stage. Follow-up } \\
\text { includes clinical and test examinations like routine } \\
\text { haematological and liver function tests, tumour } \\
\text { markers, chest X-ray, mammography, bone and liver } \\
\text { scans. There is variability in the frequency of medical } \\
\text { visits and the tests performed. }\end{array}$} \\
\hline Option: & Intensive follow-up. & & \\
\hline Comparison: & Non-intensive follow-up. & & \\
\hline Main outcomes: & $\begin{array}{l}\text { 1. 10-year mortality due to breast cancer. } \\
\text { 2. } 5 \text {-year mortality due to breast cancer. } \\
\text { 3. } 5 \text { (or 10)-year breast cancer specific survival. } \\
\text { 4. } 10 \text {-year breast cancer recurrences } \\
\text { (loco-regional and distant separately). } \\
\text { 5. } 5 \text {-year breast cancer recurrences } \\
\text { (logo-regional and distant separately). } \\
\text { 6. Quality of life of breast cancer patients } \\
\text { 2 (or 5) years after diagnosis. } \\
\text { 7. Patient satisfaction with follow-up. }\end{array}$ & & \\
\hline Setting: & Breast cancer centres/other healthcare services. & & \\
\hline Perspective: & Population. & & \\
\hline
\end{tabular}

Legend: this table represents the first part of the Evidence to Decision framework

mortality) between different types of follow-up), the important uncertainty and variability in women's values, and the cost-effectiveness of the intervention (which favours non-intensive schedules) are crucial elements in drawing conclusions.

Finally, Table 6 reports the conclusions summarised by the authors, in the form of a suggestion to perform breast cancer follow-up once a year with a mammography visit, as opposed to other types of regimens.

\section{Discussion}

\section{Main findings}

Our results showed that intensive follow-up, compared with less intensive follow-up including more frequent diagnostic test or visits, does not have beneficial effects on 5- or 10 -year overall mortality or recurrences in women with breast cancer. This finding was consistent between the studies included, and the quality of the evidence was moderate. Among the included studies, two randomised trials showed that intensive follow-up appeared to increase reassurance in patents (data on 250 women; RR 1.28, 95\% CI from 1.07 to 1.54 ) [37, 39]. However, the quality of the studies was downgraded due to the inconsistency of studies. The cost of different regimens of follow-up is variable, with more intensive regimes being more expensive but without increases in health benefits; thus less intensive regimes are favoured. From one cost-utility analysis [46], an annual visit with mammography results in moderate costs, can be considered cost-effective compared to no surveillance, and is likely to be feasible.

\section{Our results in the context of previous results}

The European Society of Medical Oncology (ESMO) Guidelines on breast cancer recommend regular visits every 3-4 months for the first 2 years after treatment (and gradually decreasing thereafter) in addition to an annual mammography [47]. American Cancer Society/ American Society of Clinical Oncology Guidelines [8] also recommend detailed cancer-related history and physical examination every 3 to 6 months for the first 3 years after primary therapy (and thereafter decreasing) in addition to a yearly mammography. Their recommendations would fall under the definition of a "less intensive follow-up" that, in the majority of the studies included in our review, would include at least a clinical visit and mammography once a year. However, intensive follow-up is still also quite common in clinical practice [48-51] and represents a significant workload for radiotherapy, surgery and oncology professionals [10], in addition to being a costly process.

A recently published systematic review on the effects of breast cancer follow-up showed that standard approaches are as effective as intensive ones; moreover, no differences in quality of life were documented [1]. While considering the health outcomes, including mortality and recurrences, our results confirm the already reported results.

\section{Limitations and strengths}

Many of the studies included in our review were carried out in previous decades, and their results might be slightly outdated, given the recent substantial changes in breast cancer care [52]; However, our study also took into account further perspectives, by including also women's preferences and values, and economic aspects, as adopted in the GRADE approach. The reviews on women's values and preferences and economic evidence were, however, limited to English and for the last ten years and Medline only, and results would have been 
Table 5 Summary of the assessment on the research question

\begin{tabular}{|c|c|c|c|}
\hline Domain & Judgement & Research evidence & Additional considerations \\
\hline \multirow[t]{7}{*}{ Problem } & Is the problem a priority? & \multirow{7}{*}{$\begin{array}{l}\text { With over 458,000 new cases and 131,000 deaths per year, } \\
\text { breast cancer is one of the main killers in Europe, and its } \\
\text { diagnosis, treatment and follow-up represent major public } \\
\text { health priorities. } \\
\text { Despite the doubts that intensive follow-up care could im- } \\
\text { prove survival in patients after breast cancer, intensive follow- } \\
\text { up is quite common in clinical practice and represents a } \\
\text { significant workload for radiotherapy, surgical and oncologic } \\
\text { departments (Loprinzi 1994), and it is also costly. }\end{array}$} & \\
\hline & $\circ \mathrm{No}$ & & \\
\hline & o Probably no & & \\
\hline & - Probably yes & & \\
\hline & ○ Yes & & \\
\hline & - Varies & & \\
\hline & ○ Don't know & & \\
\hline \multirow[t]{7}{*}{ Desirable effects } & $\begin{array}{l}\text { How substantial are the } \\
\text { desirable anticipated } \\
\text { effects? }\end{array}$ & \multirow{7}{*}{$\begin{array}{l}\text { The evidence showed uncertain differences in overall mortality } \\
\text { at } 5 \text { and } 10 \text {-year follow-up (high quality evidence), and } \\
\text { uncertain differences in recurrences at } 5 \text { years of follow-up } \\
\text { (moderate quality evidence). } \\
\text { The evidence showed significant differences in reassurance of } \\
\text { women in favour of intensive follow-up (very low quality } \\
\text { evidence), and convenience in favour of non-intensive follow- } \\
\text { up (low quality evidence). } \\
\text { There was missing research evidence in respect to the } \\
\text { outcomes: } 5 \text { and } 10 \text {-year breast cancer specific survival, 10-year } \\
\text { breast cancer recurrences and quality of life of breast cancer } \\
\text { patients } 2 \text { or } 5 \text { years after diagnosis. }\end{array}$} & \\
\hline & - Trivial & & \\
\hline & ○ Small & & \\
\hline & - Moderate & & \\
\hline & - Large & & \\
\hline & - Varies & & \\
\hline & o Don't know & & \\
\hline \multirow[t]{7}{*}{$\begin{array}{l}\text { Undesirable } \\
\text { Effects }\end{array}$} & $\begin{array}{l}\text { How substantial are the } \\
\text { undesirable anticipated } \\
\text { effects? }\end{array}$ & & \multirow[t]{7}{*}{$\begin{array}{l}\text { Undesirable health effects are related } \\
\text { to mental health (stress for false } \\
\text { positive, false reassurance for false } \\
\text { negative). }\end{array}$} \\
\hline & ○ Large & & \\
\hline & ○ Moderate & & \\
\hline & o Small & & \\
\hline & - Trivial & & \\
\hline & - Varies & & \\
\hline & o Don't know & & \\
\hline \multirow[t]{6}{*}{$\begin{array}{l}\text { Certainty of } \\
\text { evidence }\end{array}$} & $\begin{array}{l}\text { What is the overall } \\
\text { certainty of the evidence } \\
\text { of effects? }\end{array}$ & \multirow{6}{*}{$\begin{array}{l}\text { The evidence on 5- and 10- year overall mortality was of high } \\
\text { quality, and did not favour intensive versus standard follow-up. } \\
\text { The evidence on 5-year cancer recurrences was of moderate } \\
\text { quality, and there were uncertain differences between inten- } \\
\text { sive and standard follo-up; similar conclusions apply to cancer } \\
\text { recurrences at any time. } \\
\text { The evidence of women satisfaction was of very low quality } \\
\text { (reassurance domain) and of moderate quality (convenience } \\
\text { domain). } \\
\text { The evidence on values for women was of low quality } \\
\text { (inconsistency among studies). } \\
\text { The evidence on economic evaluations was of high quality, } \\
\text { and favoured non-intensive follow-up. }\end{array}$} & \\
\hline & ○ Very low & & \\
\hline & $\circ$ Low & & \\
\hline & - Moderate & & \\
\hline & $\circ$ High & & \\
\hline & - No included studies & & \\
\hline \multirow[t]{6}{*}{ Values } & $\begin{array}{l}\text { Is there important } \\
\text { uncertainty about or } \\
\text { variability in how much } \\
\text { people value the main } \\
\text { outcomes? }\end{array}$ & \multirow[t]{6}{*}{$\begin{array}{l}\text { Important variability was present among studies and within } \\
\text { studies regarding women preferences for the intensity of } \\
\text { follow-up (moderate confidence) (Gulliford 1997, Stemmler } \\
\text { 2008, Kimman 2010). }\end{array}$} & \\
\hline & $\begin{array}{l}\text { - Important uncertainty } \\
\text { or variability }\end{array}$ & & \\
\hline & $\begin{array}{l}\text { - Possibly important } \\
\text { uncertainty or variability }\end{array}$ & & \\
\hline & $\begin{array}{l}\text { - Probably no important } \\
\text { uncertainty or variability }\end{array}$ & & \\
\hline & $\begin{array}{l}\text { o No important } \\
\text { uncertainty or variability }\end{array}$ & & \\
\hline & $\begin{array}{l}\text { - No known undesirable } \\
\text { outcomes }\end{array}$ & & \\
\hline
\end{tabular}


Table 5 Summary of the assessment on the research question (Continued)

\begin{tabular}{|c|c|}
\hline Domain & Judgement \\
\hline \multirow[t]{8}{*}{$\begin{array}{l}\text { Balance of } \\
\text { effects }\end{array}$} & $\begin{array}{l}\text { Does the balance } \\
\text { between desirable and } \\
\text { undesirable effects favour } \\
\text { the intervention or the } \\
\text { comparison? }\end{array}$ \\
\hline & - Favours the comparison \\
\hline & $\begin{array}{l}\text { - Probably favours the } \\
\text { comparison }\end{array}$ \\
\hline & $\begin{array}{l}\text { o Does not favour either } \\
\text { the intervention or the } \\
\text { comparison }\end{array}$ \\
\hline & $\begin{array}{l}\text { o Probably favours the } \\
\text { intervention }\end{array}$ \\
\hline & - Favours the intervention \\
\hline & - Varies \\
\hline & o Don't know \\
\hline
\end{tabular}

Resources required

Certainty of evidence of required resources

Cost effectiveness
How large are the resource requirements (costs)?

$\circ$ Large costs

- Moderate costs

$\circ$ Negligible costs and savings

- Moderate savings

- Large savings

- Varies

- Don't know

What is the certainty of the evidence of resource requirements (costs)?

o very low

- Low

- Moderate

$\circ$ High

o No included studies

Does the cost-

effectiveness of the intervention favour the intervention or the comparison?

- Favours the comparison

- Probably favours the comparison

- Does not favour either the intervention or the comparison

- Probably favours the intervention

o Favours the intervention

- Varies

○ No included studies

Research evidence

Additional considerations

The evidence on health outcomes favours the comparison.

The evidence on values for women is unclear: reassurance

seems to favour the intervention (very low quality evidence),

while convenience seems to favour the comparison (moderate quality evidence).The evidence on health outcomes favours the comparison.

Moderate costs for the annual mammography option.

Large costs could result for more intensive follow-up schedules that could include more than one mammography per year,

clinical examinations, or MRI, or bone scans or others. Moderate costs for the annual mammography option.

Evidence comes from a good quality cost-utility analysis study from the UK (Robertson 2011).

In the base-case scenario of a cost-utility analysis of different follow-up strategies carried out in the UK, the strategy with the highest net benefit, and most likely to be considered costeffective, was surveillance mammography alone every 12 months at a societal willingness to pay for a qualityadjusted life year of either $£ 20,000$ or $£ 30,000$. The incremental Even though different countries use different cost per QALY thresholds for deciding which interventions will be funded by public health services, $€$ 6051 is far below the threshold used cost-effectiveness ratio for surveillance mammography alone every 12 months compared with no surveillance was $€ 6051$ (2008 value) (Robertson 2011). 
Table 5 Summary of the assessment on the research question (Continued)

\begin{tabular}{|c|c|c|}
\hline Domain & Research evidence & Additional considerations \\
\hline \multirow[t]{8}{*}{ Equity } & $\begin{array}{l}\text { What would be the } \\
\text { impact on health equity? }\end{array}$ & \multirow{8}{*}{$\begin{array}{l}\text { With less intensive follow-up strat- } \\
\text { egies, resources could be mobilised } \\
\text { to other aspects of breast cancer care } \\
\text { or other areas of health care that } \\
\text { could increase equity. }\end{array}$} \\
\hline & ○ Reduced & \\
\hline & - Probably reduced & \\
\hline & - Probably no impact & \\
\hline & - Probably increased & \\
\hline & ○ Increased & \\
\hline & ○ Varies & \\
\hline & o Don't know & \\
\hline \multirow[t]{7}{*}{ Acceptability } & $\begin{array}{l}\text { Is the intervention } \\
\text { acceptable to key } \\
\text { stakeholders? }\end{array}$ & \multirow{7}{*}{$\begin{array}{l}\text { Some patients, relatives and health } \\
\text { professionals might find it } \\
\text { unacceptable to reduce the number } \\
\text { of visits and tests performed. }\end{array}$} \\
\hline & $\circ \mathrm{No}$ & \\
\hline & o Probably no & \\
\hline & - Probably yes & \\
\hline & ○ Yes & \\
\hline & - Varies & \\
\hline & o Don't know & \\
\hline \multirow[t]{7}{*}{ Feasibility } & $\begin{array}{l}\text { Is the intervention feasible } \\
\text { to implement? }\end{array}$ & \multirow{7}{*}{$\begin{array}{l}\text { Settings with more intensive follow- } \\
\text { up strategies will need to consider } \\
\text { what is the impact of implementing } \\
\text { less intensive strategies (e.g. relocate } \\
\text { healthcare professionals or } \\
\text { equipment). }\end{array}$} \\
\hline & $\circ \mathrm{No}$ & \\
\hline & o Probably no & \\
\hline & - Probably yes & \\
\hline & o Yes & \\
\hline & ○ Varies & \\
\hline & o Don't know & \\
\hline
\end{tabular}

Legend: This table is the second part of the Evidence to Decision framework

more robust if such reviews were carried out with a broader scope. Moreover, the suggestion for less intensive follow-up was built by using the EtD: this is a new approach in the clinical oncology field, but has been previously used already in breast cancer screening [53], colon cancer screening [54], as well as in other contexts [55]. The EtD explicitly takes into account factors related, among others, to the quality of evidence, desirable and undesirable effects, values, resources and feasibility, that altogether constitute a comprehensive approach to a decision-making exercise. The suggestion reported in this paper was made by a multidisciplinary group of authors, but it should not be considered as a recommendation from a guideline panel.

\section{Implications for practice and research}

The main expectation from an intensified follow-up from a women's perspective was reassurance and increased sense of security. This finding raises the need to better inform women on the lack of evidence of effect of intensive follow-up on clinical outcomes of mortality and recurrences. However, it needs to be considered that the follow-up visit may also have additional aims than detection of recurrence, such as motivating women to continue endocrine treatment during the follow-up period, providing information about long-term adverse effects of treatment, and helping in their management, as well as providing psychosocial support [56]. These other aims of follow-up are very important in the light of the high prevalence of e.g., depression (varying from 9.4\% to $66.1 \%$ ), and anxiety (varying from $17.9 \%$ to $33.3 \%$ ) among breast cancer survivors [12]. These additional aspects should not be neglected and they should be better explored while evaluating the effects of different follow-up strategies. Hence, further well-designed studies should be performed. There is a need to balance and prioritise these different outcomes, including also additional patientcentred endpoints described above, as well as including undesirable effects of more frequent investigations. Moreover, organisational aspects related to the coordination of follow-up activities (i.e. nurse-led and GP-led activities, etc.) are only analysed in few studies [57] and should be 
Table 6 Authors' conclusions and summary remarks on the research question

\begin{tabular}{|c|c|c|c|c|c|}
\hline \multicolumn{6}{|c|}{ Should women be followed intensively after breast cancer treatment? } \\
\hline \multirow[t]{2}{*}{ Type of recommendation } & $\begin{array}{l}\text { Strong } \\
\text { recommendation } \\
\text { against the option }\end{array}$ & $\begin{array}{l}\text { Conditional } \\
\text { recommendation } \\
\text { against the option }\end{array}$ & $\begin{array}{l}\text { Conditional } \\
\text { recommendation for } \\
\text { either the option or the } \\
\text { comparison }\end{array}$ & $\begin{array}{l}\text { Conditional } \\
\text { recommendation } \\
\text { for the option }\end{array}$ & $\begin{array}{l}\text { Strong } \\
\text { recommendation } \\
\text { for the option }\end{array}$ \\
\hline & $\circ$ & $\bullet$ & o & $\circ$ & 0 \\
\hline Recommendation & \multicolumn{5}{|c|}{$\begin{array}{l}\text { We suggest that women with breast cancer are followed-up once a year with a mammography } \\
\text { (as opposed to other regimens) (provisional and conditional recommendation). }\end{array}$} \\
\hline Justification & \multicolumn{5}{|c|}{$\begin{array}{l}\text { There is moderate certainty of evidence that intensive follow-up compared with less intensive } \\
\text { follow-up (more frequent diagnostic tests or visits) does not reduce 5-10-year overall mortality } \\
\text { and recurrences in women with breast cancer. The cost of different regimens of follow-up is } \\
\text { variable, with more intensive regimens being more expensive and cost-effectiveness favouring } \\
\text { less intensive regimens. Resources could be mobilised to other aspects of breast cancer care, or } \\
\text { other areas of healthcare, potentially increasing equity. } \\
\text { This recommendation is provisional because of the uncertainty about the net benefit of the interventions. } \\
\text { This recommendation is conditional because it might be different depending on the feasibility } \\
\text { of the setting of the intensive follow-up policy. }\end{array}$} \\
\hline Subgroup considerations & \multicolumn{5}{|c|}{ Not applicable (no specific subgroup of women were considered). } \\
\hline Implementation considerations & \multicolumn{5}{|c|}{$\begin{array}{l}\text { Women should be informed in detail at baseline about different types of follow-up and their } \\
\text { related impacts, to increase their satisfaction and reassurance with a less intensive follow-up. } \\
\text { Resources could be mobilised to other aspects of breast cancer care, or other areas of health } \\
\text { care, potentially increasing equity. }\end{array}$} \\
\hline Monitoring and evaluation & \multicolumn{5}{|c|}{ Health outcomes related to less intensive follow-up should be periodically assessed (we suggest every 5 years). } \\
\hline Research priorities & \multicolumn{5}{|c|}{$\begin{array}{l}\text { Patient-centred endpoints should be explored, and the relationship between follow-up intensity } \\
\text { and technical and psychological support to continue endocrine treatment should be further studied. } \\
\text { Similarly, organisational aspects related to the coordination of follow-up activities should be addressed. }\end{array}$} \\
\hline
\end{tabular}

Legend: This table represents the third and last part of the Evidence to Decision framework

better explored, as they may impact on the acceptance of the protocol by women, healthcare providers, etc. as well as on costs and feasibility.

From the clinical point of view, annual mammography is well justified to detect potential new primary or local recurrences. On the contrary more intensive follow-up schedules including additional diagnostic tests, such as breast MRI, liver ultrasound or bone scans could result in large costs without sufficient evidence regarding their benefits or harms.

In summary, based on these findings, less intensive follow-up could be recommended, although the exact format of the follow-up visit would need to be further clarified, as the studies used quite different follow-up schedules and tests. The treatment of breast cancer has become increasingly individualised [58] as the risk of breast cancer recurrences is very variable and is related, among other variables, to genetic predisposition of individual women, breast cancer characteristics and its treatment. Therefore, also the follow-up should be individualised based on the risk estimates, and on women's perceptions and values. A "one size fits all" approach may not be relevant.

\section{Conclusion}

Based on the evaluation of clinical and economical outcomes carried out, a less intensive follow-up could be recommended. Patients should be provided with accurate information on the benefits (or lack of those) and harms of intensive follow-up. Resources could thus be mobilised to other aspects of breast cancer care, or other areas of healthcare, potentially increasing equity in society.

\section{Additional files}

Additional file 1: Search strategy for the evidence of effects. (DOCX $100 \mathrm{~kb}$ )

Additional file 2: Search strategy for women's values and preferences evidence. (DOCX $95 \mathrm{~kb}$ )

Additional file 3: Search strategy for economic evidence. (DOCX 97 kb)

\begin{abstract}
Abbreviations
CERQual: Confidence in the Evidence from Reviews of Qualitative research; $\mathrm{Cl}$ : Confidence intervals; EtD: Evidence to Decision; GRADE: Grading of Recommendations Assessment, Development, and Evaluation; HR: Hazard ratios; ICER: Incremental Cost Effectiveness Ratio; OR: Odds ratios; PICO: Patient, Intervention, Comparison, Outcomes; QALY: Quality Adjusted Life Years; RR: Risk ratios
\end{abstract}

\section{Acknowledgements}

The authors wish to acknowledge the contribution of the European Commission Initiative on Breast Cancer (ECIBC) Quality Assurance Scheme Developing Group (QASDG) for having rated the outcomes and provided comments to the preliminary results of the systematic review.

\section{Funding}

Administrative Arrangement SANCO/2012/C - 17.030600/12//SI2.635313 between the European Commission Directorate-General Health and Food Safety and the Directorate-General Joint Research Centre. 


\section{Availability of data and materials}

The datasets used and/or analysed during the current study available from the corresponding author on reasonable request.

\section{Authors' contributions}

$M J M Z, P A C, D R, I S$ and MP conducted the systematic review, the evidence to decision framework and the wrote the corresponding report. $L P, S D, D L, A B$, $L N, M J M Z$ and ZSP contributed to the interpretation of results. AL, LP and SD were major contributors in writing the manuscript. All authors read and approved the final manuscript

\section{Ethics approval and consent to participate}

Not applicable.

\section{Consent for publication}

Not applicable.

\section{Competing interests}

The authors declare that they have no competing interests.

\section{Publisher's Note}

Springer Nature remains neutral with regard to jurisdictional claims in published maps and institutional affiliations.

\section{Author details \\ 'CESP, School of Medicine, Università degli Studi Milano Bicocca, Monza, MB, Italy. ${ }^{2}$ Department of International Health, FHML, CAPHRI, Maastricht University, Maastricht, Netherlands. ${ }^{3}$ Cancer Society of Finland, Helsinki, Finland. ${ }^{4}$ European Commission, Directorate General Joint Research Centre (JRC), Directorate F - Health, Consumers and Reference Materials, Ispra, VA, Italy. ${ }^{5}$ Iberoamerican Cochrane Centre - Service of Clinical Epidemiology and Public Health, Biomedical Research Institute Sant Pau (IIB Sant Pau), Barcelona, Spain}

Received: 29 December 2016 Accepted: 5 October 2017

Published online: 19 October 2017

\section{References}

1. Boyle P, Levin B. World cancer report. Lyon: IARC Press; 2008.

2. Ban KA, Godellas CV. Epidemiology of breast cancer. Surg Oncol Clin N Am. 2014;23:409-22.

3. Tao Z, Shi A, Lu C, Song T, Zhang Z, Zhao J. Breast cancer: epidemiology and etiology. Cell Biochem Biophys. 2015;72:333-8.

4. Coleman MP, Quaresma M, Berrino F, Lutz JM, De Angelis R, Capocaccia R, Bail P, Rachet B, Gatta G, Hakulinen T, et al. Cancer survival in five continents: a worldwide population-based study (CONCORD). Lancet Oncol. 2008:9:730-56.

5. Ferlay J, Soerjomataram I, Dikshit R, Eser S, Mathers C, Rebelo M, Parkin DM, Forman D, Bray F. Cancer incidence and mortality worldwide: sources, methods and major patterns in GLOBOCAN 2012. Int J Cancer. 2015;136:E359-86.

6. Siegel R, Naishadham D, Jemal A. Cancer statistics, 2012. CA Cancer J Clin. 2012;62:10-29.

7. WHO. GLOBOCAN 2012: Estimated Cancer Incidence, Mortality and Prevalence Worldwide in 2012. http://globocan.iarc.fr/Default.aspx. Accessed 13 Oct 2017.

8. Khatcheressian JL, Hurley P, Bantug E, Esserman LJ, Grunfeld E, Halberg F, Hantel A, Henry NL, Muss HB, Smith TJ, et al. Breast cancer follow-up and management after primary treatment: American Society of Clinical Oncology clinical practice guideline update. J Clin Oncol. 2013;31:961-5.

9. Elmore JG, Armstrong K, Lehman CD, Fletcher SW. Screening for breast cancer. JAMA. 2005;293:1245-56.

10. Loprinzi $\mathrm{CL}$. It is now the age to define the appropriate follow-up of primary breast cancer patients. J Clin Oncol. 1994;12:881-3.

11. Moschetti I, Cinquini M, Lambertini M, Levaggi A, Liberati A. Follow-up strategies for women treated for early breast cancer. Cochrane Database Syst Rev. 2016:CD001768.

12. Maass SW, Roorda C, Berendsen AJ, Verhaak PF, de Bock GH. The prevalence of long-term symptoms of depression and anxiety after breast cancer treatment: a systematic review. Maturitas. 2015;82:100-8.
13. Niessen LW, Bridges J, Lau BD, Wilson RF, Sharma R, Walker DG, Frick KD Bass EB. Assessing the impact of economic evidence on policymakers in health care-a systematic review. Rockville: AHRQ Publication; 2012.

14. Treweek S, Oxman AD, Alderson P, Bossuyt PM, Brandt L, Brozek J, Davoli M, Flottorp S, Harbour R, Hill S, et al. Developing and evaluating communication strategies to support informed decisions and practice based on evidence (DECIDE): protocol and preliminary results. Implement Sci. 2013;8:6.

15. Guyatt GH, Oxman AD, Vist GE, Kunz R, Falck-Ytter Y, Alonso-Coello P, Schünemann HIGRADE. An emerging consensus on rating quality of evidence and strength of recommendations. BMJ. 2008;336:924-6.

16. Guyatt G, Oxman AD, Akl EA, Kunz R, Vist G, Brozek J, Norris S, Falck-Ytter Y, Glasziou P, DeBeer H, et al. GRADE guidelines: 1. Introduction-GRADE evidence profiles and summary of findings tables. J Clin Epidemiol. 2011;64:383-94.

17. Iorio A, Spencer FA, Falavigna M, Alba C, Lang E, Burnand B, McGinn T, Hayden J, Williams K, Shea B, et al. Use of GRADE for assessment of evidence about prognosis: rating confidence in estimates of event rates in broad categories of patients. BMJ. 2015; h870:350.

18. Langendam MW, Akl EA, Dahm P, Glasziou P, Guyatt G, Schunemann HJ. Assessing and presenting summaries of evidence in Cochrane reviews. Syst Rev. 2013;2:81.

19. Higgins JPT, Altman DG, Sterne JAC. Chapter 8: assessing risk of bias in included studies. In: Higgins JPT, green S (editors). Cochrane handbook for systematic reviews of interventions version 5.1.0 [updated march 2011]. The Cochrane collaboration; 2011.

20. World Health Organization. WHO handbook for guideline development Geneva: WHO. Library. 2012;

21. Balshem $H$, Helfand $M$, Schunemann HJ, Oxman AD, Kunz R, Brozek J, Vist GE, Falck-Ytter Y, Meerpohl J, Norris S, et al. GRADE guidelines: 3. Rating the quality of evidence. J Clin Epidemiol. 2011;64:401-6.

22. Schünemann H, Brożek J, Guyatt G, Oxman A. Quality of evidence. In: Schünemann H, Brożek J, Guyatt G, Oxman a (editors). GRADE handbook for grading quality of evidence and strength of recommendations. Updated October 2013. The GRADE working. Group. 2013;

23. DerSimonian R, Laird N. Meta-analysis in clinical trials. Control Clin Trials. 1986:7:177-88.

24. Moher D, Shamseer L, Clarke M, Ghersi D, Liberati A, Petticrew M, Shekelle P, Stewart LA. Preferred reporting items for systematic review and metaanalysis protocols (PRISMA-P) 2015 statement. Syst Rev. 2015;4:1.

25. Lewin S, Glenton C, Munthe-Kaas H, Carlsen B, Colvin CJ, Gulmezoglu M, Noyes J, Booth A, Garside R, Rashidian A. Using qualitative evidence in decision making for health and social interventions: an approach to assess confidence in findings from qualitative evidence syntheses (GRADE-CERQual). PLoS Med. 2015;12:10.

26. Brunetti M, Shemilt I, Pregno S, Vale L, Oxman AD, Lord J, Sisk J, Ruiz F, Hill S, Guyatt GH, et al. GRADE guidelines: 10. Considering resource use and rating the quality of economic evidence. J Clin Epidemiol. 2013;66:140-50.

27. NICE. Appendix G: Methodology checklist: economic evaluations; 2012. https://www.nice.org.uk/process/pmg6/resources/the-guidelines-manualappendices-bi-2549703709/chapter/appendix-g-methodology-checklisteconomic-evaluations. Accessed 20 Dec 2016

28. Schünemann $H$, Brożek J, Guyatt $G$, Oxman A. Summarizing the evidence. In: Schünemann H, Brożek J, Guyatt G, Oxman a (editors). GRADE handbook for grading quality of evidence and strength of recommendations. Updated October 2013. The GRADE working. Group. 2013;

29. GRADE/DECIDE. Interactive Evidence to Decision Frameworks. http://ietd. epistemonikos.org/\#/help?show=guidance. Accessed 13 Oct 2017.

30. Collins RF, Bekker HL, Dodwell DJ. Follow-up care of patients treated for breast cancer: a structured review. Cancer Treat Rev. 2004;30:19-35.

31. Montgomery DA, Krupa K, Cooke TG. Follow-up in breast cancer: does routine clinical examination improve outcome? A systematic review of the literature. Br J Cancer. 2007;97:1632-41.

32. National Breast and Ovarian Cancer Centre. Follow-up of patients with early breast cancer. A systematic review. Surry Hills: National Breast and Ovarian Cancer Centre; 2009.

33. Robertson C, Ragupathy SK, Boachie C, Fraser C, Heys SD, Maclennan G, Mowatt G, Thomas RE, Gilbert FJ. Surveillance mammography for detecting ipsilateral breast tumour recurrence and metachronous contralateral breast cancer: a systematic review. Eur Radiol. 2011;21:2484-91.

34. Rojas MP, Telaro E, Russo A, Fossati R, Confalonieri C, Liberati A. Follow-up strategies for women treated for early breast cancer. Updated in 2012 Cochrane Database Syst Rev. 2000;4:CD001768. 
35. Impact of follow-up testing on survival and health-related quality of life in breast cancer patients. A multicenter randomized controlled trial. The GIVIO Investigators. JAMA 1994;271:1587-1592.

36. Rosselli Del Turco M, Palli D, Cariddi A, Ciatto S, Pacini P, Distante V. Intensive diagnostic follow-up after treatment of primary breast cancer. A randomized trial. National Research Council project on breast cancer followup. JAMA. 1994;271:1593-7.

37. Gulliford T, Opomu M, Wilson E, Hanham I, Epstein R. Popularity of less frequent follow up for breast cancer in randomised study: initial findings from the hotline study. BMJ. 1997;314:174-7.

38. Palli D, Russo A, Saieva C, Ciatto S, Rosselli Del Turco M, Distante V, Pacini P. Intensive vs clinical follow-up after treatment of primary breast cancer: 10year update of a randomized trial. National Research Council project on breast cancer follow-up. JAMA. 1999;281:1586

39. Brown L, Payne S, Royle G. Patient initiated follow up of breast cancer. Psychooncology. 2002;11:346-55.

40. Kokko R, Hakama M, Holli K. Role of chest X-ray in diagnosis of the first breast cancer relapse: a randomized trial. Breast Cancer Res Treat. 2003;81:33-9.

41. Kokko R, Hakama M, Holli K. Follow-up cost of breast cancer patients with localized disease after primary treatment: a randomized trial. Breast Cancer Res Treat. 2005;93:255-60.

42. Oltra A, Santaballa A, Munarriz B, Pastor M, Montalar J. Cost-benefit analysis of a follow-up program in patients with breast cancer: a randomized prospective study. Breast J. 2007;13:571-4.

43. Stemmler HJ, Lässig D, Stieber P, Bauerfeind I, Kahlert S, Fasching PA, Beckmann MW, Glattes M, Goldmann-Posch U, Hoffmann V, et al. The reality in the surveillance of breast cancer survivors-results of a patient survey. Breast Cancer (Auckl). 2008;1:17-23.

44. Kimman ML, Dellaert BG, Boersma L, Lambin P, Dirksen CD. Follow-up after treatment for breast cancer: one strategy fits all? An investigation of patient preferences using a discrete choice experiment. Acta Oncol. 2010;49:328-37.

45. Kimman ML, Dirksen CD, Voogd AC, Falger $P$, Gijsen BC, Thuring M, Lenssen A, van der Ent F, Verkeyn J, Haekens C, et al. Economic evaluation of four follow-up strategies after curative treatment for breast cancer: results of an RCT. Eur J Cancer. 2011;47:1175-85.

46. Robertson C, Arcot Ragupathy SK, Boachie C, Dixon JM, Fraser C, Hernandez R, Heys S, Jack W, Kerr GR, Lawrence G, et al. The clinical effectiveness and costeffectiveness of different surveillance mammography regimens after the treatment for primary breast cancer: systematic reviews registry database analyses and economic evaluation. Health Technol Assess. 2011;15(v-vi)

47. Senkus E, Kyriakides S, Ohno S, Penault-Llorca F, Poortmans P, Rutgers E, Zackrisson S, Cardoso F, et al. Primary breast cancer: ESMO clinical practice guidelines for diagnosis, treatment and follow-up. Ann Oncol. 2015;26(Suppl 5):v8-30.

48. Andreano A, Anghinoni E, Autelitano M, Bellini A, Bersani M, Bizzoco S. Cavalieri d'Oro L, Decarli a, Lucchi S, Mannino S, et al. indicators based on registers and administrative data for breast cancer: routine evaluation of oncologic care pathway can be implemented. J Eval Clin Pract. 2016;22:62-70.

49. Chopra I, Chopra A. Follow-up care for breast cancer survivors: improving patient outcomes. Patient Relat Outcome Meas. 2014;30(5):71-85.

50. Grandjean I, Kwast AB, de Vries H, Klaase J, Schoevers WJ, Siesling S. Evaluation of the adherence to follow-up care guidelines for women with breast cancer. Eur J Oncol Nurs. 2012;16:281-5.

51. Richert-Boe KE. Heterogeneity of cancer surveillance practices among medical oncologists in Washington and Oregon. Cancer. 1995;75:2605-12.

52. Bucchi L, Belli P, Benelli E, Bernardi D, Brancato B, Calabrese M, Carbonaro LA, Caumo F, Cavallo-Marincola B, Clauser P, et al. Recommendations for breast imaging follow-up of women with a previous history of breast cancer: position paper from the Italian Group for Mammography Screening (GISMa) and the Italian College of Breast Radiologists (ICBR) by SIRM. Radiol Med. 2016:121:891-6.

53. European Commission Initiative on Breast Cancer. Recommendations on Breast Cancer Screening. http://ecibc.jrc.ec.europa.eu/recommendations/. Accessed 13 Oct 2017

54. Alsanea N, Almadi MA, Abduljabbar AS, Alhomoud S, Alshaban TA, Alsuhaibani A, Alzahrani A, Batwa F, Hassan AH, Hibbert D, et al. National Guidelines for colorectal cancer screening in Saudi Arabia with strength of recommendations and quality of evidence. Ann Saudi Med. 2015;35:189-95.

55. Gonzalez-Lorenzo M, Piatti A, Coppola L, Gramegna M, Demicheli V, Melegaro A, Tirani M, Parmelli E, Auxilia F, Moja L, et al. Conceptual frameworks and key dimensions to support coverage decisions for vaccines. vaccine. 2015;33:1206-17.
56. Laporte C, Vaure J, Bottet A, Eschalier B, Raineau C, Pezet D, Vorilhon P. French women's representations and experiences of the post-treatment management of breast cancer and their perception of the general practitioner's role in follow-up care: a qualitative study. Health Expect. 2016;

57. Grunfeld E, Levine MN, Julian JA, Coyle D, Szechtman B, Mirsky D, Verma S, Dent S, Sawka C, Pritchard Kl, et al. Randomized trial of long-term follow-up for early-stage breast cancer: a comparison of family physician versus specialist care. J Clin Oncol. 2006;24:848-55.

58. Cho SH, Jeon J, Kim SI. Personalized medicine in breast cancer: a systematic review. J Breast Cancer. 2012;15:265-72.

\section{Submit your next manuscript to BioMed Central and we will help you at every step:}

- We accept pre-submission inquiries

- Our selector tool helps you to find the most relevant journal

- We provide round the clock customer support

- Convenient online submission

- Thorough peer review

- Inclusion in PubMed and all major indexing services

- Maximum visibility for your research

Submit your manuscript at www.biomedcentral.com/submit
) Biomed Central 